\title{
Association of Urine Lead Exposure with Lipid Metabolism Risk Factors and Diseases in Xinxiang, China
}

\author{
Xinwen Dong', Yuanyuan Wang ${ }^{1}$, Jing Jiang ${ }^{2}$, Zhichun $\mathrm{Li}^{1}$, Weidong Wu'* \\ ${ }^{1}$ Department of Environmental and Occupational Health, School of Public Health, \\ Xinxiang Medical University, Xinxiang, Henan Province, China \\ ${ }^{2}$ Experimental Teaching Center of Public Health and Preventive Medicine, School of Public Health, \\ Xinxiang Medical University, Xinxiang, Henan Province, China
}

Received: 7 October 2019

Accepted: 21 November 2019

\begin{abstract}
Exposure to lead $(\mathrm{Pb})$ in environmental and occupational settings is still a serious public health problem and may pose an elevated risk for developing metabolic disorders. The aim of this study is to investigate urine lead levels and lipid metabolism in residents of areas surrounding Xinxiang city, and to examine the relationship between urine lead levels and lipid metabolism in the area's residents in order to provide a scientific basis for the prevention and management of lipid metabolism diseases and environmental management of the relevant departments in this area. Residents in the surrounding areas of Xinxiang city were selected and stratified successively. A stratified cluster questionnaire was used to collect data and conduct a physical examination, and blood lipid levels and urine metal levels were analyzed. There was a significant positive correlation between the levels of lead in the urine and the amount of triglycerides in the samples $(\mathrm{P}<0.05)$. Urine lead levels in the hyperlipidemia group were significantly higher than those in the normal group $(\mathrm{P}<0.05)$. The risk of hyperlipidemia increased by 1.332 times $(95 \% \mathrm{CI}=1.055-1.682)$ for each quartile interval of urine lead concentration. This study confirmed that the urine lead level was significantly correlated with all metabolic syndrome variables. Lead content and lead emission in the environment should be reduced so as to reduce the occurrence of hyperlipidemia.
\end{abstract}

Keywords: heavy metals, lead exposure, lipid metabolism, urine

\section{Introduction}

With social and economic improvements often comes an increase in environmental pollution, which is becoming more worrisome and can have many adverse effects on the lives of local residents through atmosphere, soil and water exposure [1]. Therefore, increasing attention is being paid toward environmental pollution problems, including heavy metal pollution. Heavy metals such as lead are serious environmental pollutants and their impact on human health should 
not be ignored. Studies have shown that various acute and chronic diseases caused by lead exposure affect human health enormously. The health hazards caused by lead exposure are multifaceted and multi-system. Lead exposure can damage the nervous, immune and digestive systems, as well as many other bodily systems $[2,3]$. China's rapid economic development has not only brought environmental pollution problems, but also improved people's living standards and greatly improved residents' diet. Therefore, diseases related to abnormal lipid metabolism have become common and can seriously threaten residents' health and life expectancy by increasing the risk of developing other diseases.

Dyslipidemia is a common disease that can lead to atherosclerosis and increase the risk of coronary heart disease and ischemic stroke [4]. Studies have shown that the incidence of abnormal lipid metabolism is increasing each year, and lipid metabolism disorder can increase the risk of cardiovascular disease and the incidence of related diseases [5]. Current studies have shown that there is a dose-response relationship between urinary metal levels and coronary heart disease $[6,7]$. Notably, a previous study showed that dysfunction of the hypothalamus-pituitary-thyroid network was activated after exposure to lead, leading to an increase in perioxidation products, a decrease in antioxidant defense resources, and altered lipid metabolism - ultimately leading to the onset of obesity, suggesting that increased lead serum levels can increase the risk of lipid metabolism disorders [8].

These results underscore the notion that preventing lead exposure and the lipid metabolism diseases it causes is important and requires widespread attention. Although several studies on the levels of lead in urine have already been carried out, studies on its relationship with lipid metabolism diseases are scarce. We therefore conducted an epidemiological study on the relationship between lead urine levels and lipid metabolism in Xinxiang County residents in China in order to reveal the damage caused by heavy metal pollution, minimize the population burden of lipid-metabolism-related diseases, formulate prevention measures, and improve the residents' quality of life.

\section{Material and Methods}

\section{Research Objects}

A stratified cluster sampling method was used to select the surrounding areas of Xinxiang city (Qiliying, Langgongmiao, Guandi, Hehe, Xiaoji, Hongqi District, Muye District, Weibin District, Ye County, and Hui County). A total of 1022 residents in the areas listed above participated in the questionnaire survey and provided their urine samples. The subjects were 21-85 years old. All subjects were aware of the significance of this study and provided informed consent.

\section{Exclusion Criteria}

In a total of 1022 people, we failed to detect the lead concentration in samples provided by 26 survey subjects, leading to the exclusion of those subjects from this study. In addition, 2 cases with missing data for hyperlipidemia were excluded from this study. In total, 994 subjects were included in our analysis.

\section{Research Methods and Contents}

All the investigators were members of the research group and had undergone strict training. They used a unified questionnaire to investigate the basic conditions of the population. The questionnaire survey and physical examination were carried out on the individuals who met the survey conditions in place for this cross-sectional study. Blood and urine samples of each subject were collected and brought back to the laboratory for testing in order to obtain the data needed for this study. The questionnaire included general demographic information (including name, gender, date of birth, nationality and native place), previous medical history (such as hypertension and hyperlipidemia), and medication history (such as antihypertensive drugs and lipid-lowering drugs). Physical examination included measuring height, weight, waist circumference, hip circumference, blood pressure, conducting an electrocardiogram, etc. The urina sanguinis of 994 residents was collected and a urinary lead test was conducted according to WS/ T17-1996. Residents whose urine lead levels exceeded $0.07 \mathrm{mg} / \mathrm{L}$ were diagnosed using the occupational diagnostic criteria for chronic lead poisoning (GBZ372002). All experimental protocols and procedures were approved by the Committee of Xinxiang Medical University (Xinxiang, China).

\section{Variable Definition}

Patients with abnormal lipid metabolism were defined as those with total cholesterol greater than $5.72 \mathrm{mmol} / \mathrm{L}$ and triglyceride levels greater than 1.70 $\mathrm{mmol} / \mathrm{L}$. Patients with hypertension were defined as those with systolic blood pressure greater than or equal to $140 \mathrm{mmHg}$ and diastolic blood pressure greater than or equal to $90 \mathrm{mmHg}$. Body mass index (BMI) was calculated using the following equation, $\mathrm{BMI}=$ weight $(\mathrm{Kg}) /$ height $^{2}\left(\mathrm{~m}^{2}\right)$.

\section{Statistical Analysis}

SPSS 17.0 software was used for statistical analysis of the data. The differences in urine lead levels among different genders and age groups were compared. The influence factors were analyzed by binary logistic 
regression. Normal distribution data were described as mean \pm standard deviation, and a t-test was used to compare the differences between the two groups. Data of non-normal distribution were described using median and interquartile interval, and the differences between the two groups were compared using a nonparametric test. Pearson rank correlation was used to analyze the relationship of urine lead levels and blood lipids levels. Binary logistic regression was used to analyze the regression relationship between hyperlipidemia and urinary metal quartile and BMI, and the odds ratio (OR) and $95 \%$ CI were calculated. $\mathrm{P}<0.05$ was considered to be a statistically significant difference.

\section{Results}

\section{Demographic Characteristics of Research Objects}

A total of 994 subjects were included in the statistical analysis for this study, including 64 with hyperlipidemia and 930 with normal lipids. The study included 399 males (40.1\%) and 531 females (53.4\%), and the mean age and body mass index of the subjects with normal blood lipids were $54.67 \pm 12.24$ years old and $25.57 \pm 3.52 \mathrm{Kg} / \mathrm{m}^{2}$, respectively. There were 193
(20.8\%) subjects with hypertension. The urine lead content (P50, percentile) in hyperlipidemia group and normal blood lipid group were 2.52 and $1.97 \mu \mathrm{g} / \mathrm{L}$, respectively. The mean concentrations of triglyceride and total cholesterol in these subjects were $1.54 \pm 1.33$ and $4.28 \pm 0.97 \mathrm{mmol} / \mathrm{L}$, respectively. There were 64 subjects with hyperlipidemia, including 26 males (6.1\%) and 38 females (6.7\%). The mean age and BMI of the hyperlipidemia patients were $60.91 \pm 9.10$ years old and $27.11 \pm 3.15 \mathrm{Kg} / \mathrm{m}^{2}$, respectively, and 33 of the hyperlipidemia subjects $(51.6 \%)$ had hypertension. The mean concentrations of triglyceride and total cholesterol in the hyperlipidemia subjects were $2.21 \pm 1.05$ and $5.68 \pm 1.57 \mathrm{mmol} / \mathrm{L}$, respectively. These results are summarized in Table 1.

\section{The Relationship between Lead and Lipid Levels}

Lipid levels can be used as a diagnostic index for lipid metabolism disorders and related diseases. The determination of total cholesterol can identify the risk of atherosclerosis early, and the determination of triglyceride levels early can identify both the risk of atherosclerosis and the classification of hyperlipidemia. In this study, there was a significant positive correlation between urine lead levels and triglyceride levels $(P<0.05)$. The results are shown in Table 2 .

Table 1. Basic characteristics and clinical indicators of population.

\begin{tabular}{|c|c|c|c|}
\hline Variable & $\begin{array}{l}\text { Normal lipid group } \\
\qquad(\mathrm{n}=930)\end{array}$ & $\begin{array}{l}\text { Hyperlipidemia group } \\
\qquad(\mathrm{n}=64)\end{array}$ & $\begin{array}{l}\text { Total population } \\
\quad(\mathrm{n}=994)\end{array}$ \\
\hline Age (years) & $54.67 \pm 12.24$ & $60.91 \pm 9.10$ & $55.07 \pm 12.15$ \\
\hline \multicolumn{4}{|c|}{ Gender } \\
\hline Male & $399(93.9)$ & $26(6.1)$ & $425(42.8)$ \\
\hline Female & $531(93.3)$ & $38(6.7)$ & $569(57.2)$ \\
\hline $\mathrm{BMI}\left(\mathrm{Kg} / \mathrm{m}^{2}\right)$ & $23.57 \pm 3.52$ & $27.11 \pm 3.15^{*}$ & $25.67 \pm 3.52$ \\
\hline \multicolumn{4}{|c|}{ Hypertension } \\
\hline No & $737(79.2)$ & $31(48.4)$ & $768(77.3)$ \\
\hline Yes & $193(20.8)$ & $33(51.6)$ & $226(22.7)$ \\
\hline Urine lead content $(\mu \mathrm{g} / \mathrm{L})$ & $1.97(1.98)$ & $2.52(2.71)$ & $1.98(2.09)$ \\
\hline $\mathrm{LDL}(\mathrm{mmol} / \mathrm{L})$ & $3.00 \pm 0.79$ & $3.22 \pm 1.14$ & $3.02 \pm 0.82$ \\
\hline $\mathrm{HDL}(\mathrm{mmol} / \mathrm{L})$ & $1.28 \pm 0.31$ & $1.20 \pm 0.34$ & $1.28 \pm 0.31$ \\
\hline $\mathrm{TG}(\mathrm{mmol} / \mathrm{L})$ & $1.54 \pm 1.33$ & $2.21 \pm 1.05^{*}$ & $1.77 \pm 1.32$ \\
\hline $\mathrm{TC}(\mathrm{mmol} / \mathrm{L})$ & $4.28 \pm 0.97$ & $5.68 \pm 1.57^{*}$ & $5.31 \pm 1.02$ \\
\hline \multicolumn{4}{|c|}{ Use lipid-lowering drugs } \\
\hline No & $930(100)$ & $19(29.7)$ & $949(95.5)$ \\
\hline Yes & - & $45(70.3)$ & $45(4.5)$ \\
\hline
\end{tabular}

Note: Values are expressed as mean \pm standard deviation or $\mathrm{n}(\%)$. *Compared with the normal lipid group, BMI, TC and TG are significant differences in the hyperlipidemia group, $P<0.05$. BMI, body mass index; LDL, low density lipoprotein; HDL, high density lipoprotein; TG, triglyceride; TC, total cholesterol. 
Table 2. Correlation analysis between urine lead and serum lipid levels.

\begin{tabular}{|c|c|c|c|}
\hline Lipid & $\mathrm{R}$ & $\mathrm{P}$ & $\mathrm{N}$ \\
\hline TG & $0.091^{*}$ & 0.004 & 994 \\
\hline TC & 0.058 & 0.067 & 994 \\
\hline
\end{tabular}

Note: ${ }^{*} P<0.05$ (the difference was statistically significant). N, number of samples; TG, triglyceride; TC, total cholesterol; R: linear correlation coefficient.

\section{The Relationship between Lead and Hyperlipidemia}

Hyperlipidemia is a type of disease associated with high blood fat level, which can directly cause serious diseases that endanger human health. In this study, the median and interquartile range of urine lead levels in hyperlipidemia patients and normal blood lipid group were 2.52 (median) and 2.71 (interquartile), and 1.97 (median) and 1.98 (interquartile), respectively. Statistical analysis showed that the lead content in the hyperlipidemia group was significantly higher than that in normal blood lipid group $(P<0.05)$ (Table 3$)$. In addition, increased urine lead concentration was found to be a risk factor for hyperlipidemia, and the relative risk of hyperlipidemia was 1.332 (95\% $\mathrm{CI}=1.055-1.682, P=0.016)$ for every quartile increase in lead concentration. These results suggest that lead content in hyperlipidemia patients is significantly higher than it is in the normal group, and exposure to lead may increase the risk of hyperlipidemia.

\section{The Relationship between Hyperlipidemia and $\mathrm{BMI}$}

Body mass index (BMI) is commonly used to measure the degree of obesity and health. The BMI in hyperlipidemia patients was $27.06 \pm 3.15$, which was significantly higher than the BMI of $25.57 \pm 3.50$ found in the normal lipid group $(P<0.01)$. Detailed results are shown in Table 4. In addition, BMI was divided into two groups: the normal group $(\mathrm{BMI} \leq 24)$ and the overweight and obese group (BMI>24). The regression analysis of hyperlipidemia compared to BMI showed that the risk of hyperlipidemia in the overweight and obesity group was 3.916 times that in the normal group (95\% $\mathrm{CI}=1.765-8.688, P=0.001)$, suggesting that the BMI of
Table 4. Differences of BMI in hyperlipidemia group and normal lipid group $(\mathrm{X} \pm \mathrm{S})$.

\begin{tabular}{|c|c|c|}
\hline Grouping & Mean & $\begin{array}{c}\text { Standard } \\
\text { deviation }\end{array}$ \\
\hline Hyperlipidemia group & $27.11^{*}$ & 3.15 \\
\hline Normal blood lipid group & 23.57 & 3.52 \\
\hline
\end{tabular}

Note: "Compared with normal blood lipid group, difference of BMI in hyperlipidemia group was statistically significant $P<0.01$. BMI, body mass index.

the hyperlipidemia group was significantly higher than that of the normal group, and that BMI was a risk factor for hyperlipidemia.

\section{Discussion}

Even in the current era of constant industrialization and advancement, heavy metals are the most dangerous man-made pollutants in the environment and have a wide range of pathological effects, leading to irreversible changes in organism tissues and systems. As a harmful metal, lead has adverse effects on the environment and human health, and is becoming a major health concern for both the public and health care professionals $[3,9]$. Lead has been reported to damage whole body organs such as the heart, kidney, and in particular the liver [10]. A small portion of the heavy metal that enters the body is excreted through the body's own metabolism, and the majority that remains is deposited in the body, leading to lead poisoning. The damage and dysfunction observed in lead poisoning patients can manifest in multiple organs, and death can occur in severe cases [3]. Studies by Ding N et al. have shown that lead exposure is associated with an increased risk of cardiovascular disease [11]. A systematic review of studies on lead and cardiovascular disease was performed by Navas-acien A et al. and suggested a positive correlation between lead exposure and the occurrence of cardiovascular diseases (coronary heart disease, peripheral artery disease) [12]. This was supported by a later study that reported that an increase in lead exposure is significantly positively correlated with an increase in the prevalence of cardiovascular diseases [13]. In recent years, with the significant improvement of the national economy, the diet and living habits of Chinese residents have also changed, and the number of patients with

Table 3. Difference of urine lead content in hyperlipidemia group and normal blood lipid group (percentile).

\begin{tabular}{|c|c|c|c|c|c|}
\hline Grouping & $\mathrm{N}$ & $\mathrm{P} 25$ & $\mathrm{P} 50$ & $\mathrm{P} 75$ & Range interquartile \\
\hline Hyperlipidemia group & 64 & 1.41 & $2.52^{*}$ & 4.12 & 2.71 \\
\hline Normal blood lipid group & 930 & 1.24 & 1.97 & 3.22 & 1.98 \\
\hline
\end{tabular}

Note: *Compared with the normal blood lipid group, difference of urine lead content in hyperlipidemia group was statistically significant, $P<0.05$. P25, P50, P75: quartile. 
hyperlipidemia has been on the rise each year, which can seriously harm the health of residents. Studies have shown that lipid levels can seriously affect the risk of coronary heart disease [14], and additional studies have found an association between lipid concentration and coronary atherosclerosis [15]. However, few studies have analyzed the relationship between urine metal levels and lipid metabolism.

We found that the blood lipids levels were significantly higher in women than men. This was consistent with the finding reported in a follow-up analysis on the change of serum total cholesterol (TC) concentration in Shanxi Province, which found that the serum TC level was $4.86 \pm 0.98 \mathrm{mmol} / \mathrm{L}$ in females and $4.54 \pm 0.93 \mathrm{mmol} / \mathrm{L}$ in males [16]. The result could be attributed to the fact that more women are overweight compared to men.

The results of this study show that urine lead levels are positively correlated with triglycerides, which is consistent with the experimental conclusions reached by Park YJ et al. [17]. Previous studies observed that lipid peroxidation could be caused by occupational lead exposure, and occupational lead exposure induced oxidative stress that resulted in lipid damage [18, 19], a finding similar to the results of this study. Another study also found that early-life exposure to lead was strongly correlated with obesity, which was consistent with our results showing that urine lead content had a close positive correlation with lipid metabolism [20]. At the same time, our study revealed that lead exposure is a risk factor for hyperlipidemia and increases the risk of it. This is similar to the review by Poręba R [21], who concluded that lead is a potential risk factor for cardiovascular disease. Many studies suggest that lead in urine can cause damage to the body primarily by causing oxidative stress [22]. The susceptibility of cholesterol to interactions with highly reactive substances causes its own autooxidation, which leads to the development of diseases [23]. Lead may increase the risk of hyperlipidemia by causing changes in blood lipids in response to oxidative stress. Our study also found that BMI was higher in hyperlipidemia subjects, which was consistent with the analysis of blood lipid levels and related factors performed by Booth HP et al. [24]. Together, these studies point to possible options for preventing and controlling hyperlipidemia, such as by reducing BMI to a normal level through physical activity and a proper diet.

In summary, we can reduce the risk of lipid metabolism disorders by reducing exposure to $\mathrm{Pb}$. On the other hand, it is also possible to reduce risk by controlling weight through a healthy diet and lifestyle.

\section{Conclusions}

This study found that the urine lead level was significantly correlated with all lipid metabolism variables: BMI, blood lipid, TG and blood pressure. These findings imply that the urine lead level and incidence of lipid metabolism diseases are closely correlated.

\section{Acknowledgements}

We thank our team for their valuable assistance. This research was supported by the National Key Research and Development Program "Precision Medicine Initiative" of China (grant No. 2016YFC0900803).

\section{Conflict of Interest}

The authors declare no conflict of interest.

\section{References}

1. GARCIA-ESQUINAS E., NAVAS-ACIEN A., PEREZGOMEZ B., ARTALEJO F.R. Association of lead and cadmium exposure with frailty in US older adults. Environmental research, 137, 424, 2015.

2. DENG W., LI X., AN Z., YANG L. Lead Contamination and Source Characterization in Soils Around a Lead-Zinc Smelting Plant in a Near-Urban Environment in Baoji, China. Archives of environmental contamination and toxicology, 71 (4), 500, 2016.

3. REHMAN K., FATIMA F., WAHEED I., AKASH M.S.H. Prevalence of exposure of heavy metals and their impact on health consequences. Journal of cellular biochemistry, 119 (1), 157, 2018.

4. KOPIN L., LOWENSTEIN C. Dyslipidemia. Annals of internal medicine, 167 (11), ITC81-, 2017.

5. HAMILTON L., WILSON D.P., O'REILLY C.M., GONZALEZ J., DE LA TORRE A. The Prevalence of Dyslipidemia and Other Cardiovascular Risk Factors in Youth with Diabetes. Current pediatric reviews, 13 (4), 277, 2017.

6. SPONDER M., FRITZER-SZEKERES M., MARCULESCU R., MITTLBOCK M., UHL M., KOHLER-VALLANT B., STRAMETZ-JURANEK J. Blood and urine levels of heavy metal pollutants in female and male patients with coronary artery disease. Vascular health and risk management, 10, 311, 2014.

7. TELLEZ-PLAZA M., GUALLAR E., HOWARD B.V., UMANS J.G., FRANCESCONI K.A., GOESSLER W., SILBERGELD E.K., DEVEREUX R.B., NAVAS-ACIEN A. Cadmium exposure and incident cardiovascular disease. Epidemiology, 24 (3), 421, 2013.

8. LUZHETSKYI K.P., USTINOVA O.Y., SHTINA I.E., VEKOVSHININA S.A., IVASHOVA Y.A., TSINKER M.Y. Lipid metabolism changes in population residing in area influenced by storage of ore-processing waste containing lead, cadmium and arsenic. Meditsina truda i promyshlennaia ekologiia, 8, 32, 2016.

9. BOSKABADY M., MAREFATI N., FARKHONDEH T., SHAKERI F., FARSHBAF A., BOSKABADY M.H. The effect of environmental lead exposure on human health and the contribution of inflammatory mechanisms, a review. Environment international, 120, 404, 2018. 
10. COWAN V., BLAKLEY B. Acute lead poisoning in western Canadian cattle - A 16-year retrospective study of diagnostic case records. The Canadian veterinary journal. La revue veterinaire canadienne, 57 (4), 421, 2016.

11. DING N., WANG X., WEISSKOPF M.G., SPARROW D., SCHWARTZ J., HU H., PARK S.K. Lead-Related Genetic Loci, Cumulative Lead Exposure and Incident Coronary Heart Disease: The Normative Aging Study. PloS one, 11 (9), e0161472, 2016

12. NAVAS-ACIEN A., GUALLAR E., SILBERGELD E.K., ROTHENBERG S.J. Lead exposure and cardiovascular disease--a systematic review. Environmental health perspectives, 115 (3), 472, 2007.

13. CHEN C., LI Q., NIE X., HAN B., CHEN Y., XIA F., ZHAI H., WANG N., LU Y. Association of lead exposure with cardiovascular risk factors and diseases in Chinese adults. Environmental science and pollution research international, 24 (28), 22275, 2017.

14. MORI T.A., BEILIN L.J. Long-chain omega 3 fatty acids, blood lipids and cardiovascular risk reduction. Current opinion in lipidology, 12 (1), 11, 2001.

15. SHAHAR E., CHAMBLESS L.E., ROSAMOND W.D., BOLAND L.L., BALLANTYNE C.M., MCGOVERN P.G., SHARRETT A.R. Atherosclerosis Risk in Communities S. Plasma lipid profile and incident ischemic stroke: the Atherosclerosis Risk in Communities (ARIC) study. Stroke, 34 (3), 623, 2003.

16. SONG P.K., CHEN J., XU X.G., DONG K., ZHAI Y., ZHANG M., ZHAO Y.F., WANG Z.Q., MI S.Q., ZHANG J., ZHAO W.H. Follow-up analysis on change of serum total cholesterol concentration in rural residents in Shanxi province. Zhonghua liu xing bing xue za zhi, 40 (5), 542, 2019.

17. PARK Y.J., JUNG Y., OH C.U. Relations between the blood lead level and metabolic syndrome risk factors. Public health nursing, 36 (2), 118, 2019.
18. KASPERCZYK S., SLOWINSKA-LOZYNSKA L., KASPERCZYK A., WIELKOSZYNSKI T., BIRKNER E. The effect of occupational lead exposure on lipid peroxidation, protein carbonylation, and plasma viscosity. Toxicology and industrial health, 31 (12), 1165, 2015.

19. KASPERCZYK A., DOBRAKOWSKI M., OSTALOWSKA A., ZALEJSKA-FIOLKA J., BIRKNER E. The metabolism of carbohydrates and lipid peroxidation in lead-exposed workers. Toxicology and industrial health, 31 (12), 1318, 2015.

20. PARK S.S., SKAAR D.A., JIRTLE R.L., HOYO C. Epigenetics, obesity and early-life cadmium or lead exposure. Epigenomics, 9 (1), 57, 2017.

21. POREBA R., GAC P., POREBA M., ANDRZEJAK R. Environmental and occupational exposure to lead as a potential risk factor for cardiovascular disease. Environmental toxicology and pharmacology, 31 (2), 267, 2011.

22. PAWLAS N., OLEWINSKA E., MARKIEWICZ-GORKA I., KOZLOWSKA A., JANUSZEWSKA L., LUNDH T., JANUSZEWSKA E., PAWLAS K. Oxidative damage of DNA in subjects occupationally exposed to lead. Advances in clinical and experimental medicine : official organ Wroclaw Medical University, 26 (6), 939, 2017.

23. ZERBINATI C., IULIANO L. Cholesterol and related sterols autoxidation. Free radical biology \& medicine, 111, 151, 2017.

24. BOOTH H.P., PREVOST A.T., GULLIFORD M.C. Severity of obesity and management of hypertension, hypercholesterolaemia and smoking in primary care: population-based cohort study. Journal of human hypertension, 30 (1), 40, 2016. 